\title{
Erratum to: Coarse root spatial distribution determined using a ground-penetrating radar technique in a subtropical evergreen broad-leaved forest, China
}

\author{
YAN Hui $^{1,2,3}$, DONG XinLiang ${ }^{1,2}$, FENG Gang ${ }^{1,2}$, ZHANG ShouRen $^{1 *}$ \\ \& MUCCIARDI Anthony ${ }^{4}$
}

${ }^{1}$ State Key Laboratory of Vegetation and Environmental Change, Institute of Botany, Chinese Academy of Sciences, Beijing 100093, China;

${ }^{2}$ University of Chinese Academy of Sciences, Beijing 100049, China;

${ }^{3}$ Inner Mongolia Forestry Monitoring and Planning Academy, Hohhot 010020, China;

${ }^{4}$ TreeRadar, Inc., Silver Spring, MD 20910, USA

Erratum to: Science China Life Sciences, November 2013 Vol.56 No.11: 1038-1046 doi: 10.1007/s11427-013-4560-7

The legend of Figure 1 should be as follows:

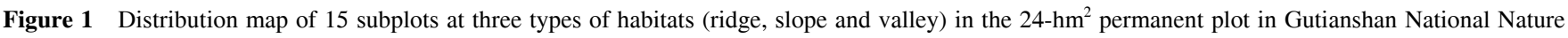
Reserve (the different digits in the map represent different habitat types).

The online version of the original article can be found at http://dx.doi.org/10.1007/s11427-013-4560-7 